\title{
DIREITO À SAÚDE E PODER JUDICIÁRIO: \\ decisões no âmbito do Tribunal de Justiça do Estado do Maranhão*
}

\author{
HEALTH LAW AND JUDICIARY: \\ decisions in the Court of Maranhão State
}

EL PODER JUDICIAL Y EL DERECHO A LA SALUD

decisiones en la esfera del Tribunal de Justicia del estado de Maranhão

\author{
Ana Karolyne Araújo de Sousa \\ Laurena Silva Pinto \\ Mônica Teresa Costa Sousa
}

\begin{abstract}
Resumo: O trabalho tem por objetivo principal analisar decisões judiciais do TJMA considerando demandas individuais relacionadas à efetivação e garantia do direito à saúde, a partir da oferta de tratamento médico/ medicamento específico por parte do Estado. Analisa-se a fundamentação das decisões e atuação do Poder Judiciário ante a defesa justificada como "reserva do possível" por parte do ente público. Com base na teoria da reserva do possível, o Estado defende-se alegando ser impossível a prestação de serviços específicos considerando ou a generalidade da política pública de saúde ou questões financeiras. Por sua vez, o Judiciário se manifesta ora considerando a pretensão individual (posicionamento mais comum) ora afastando essa possibilidade. Tomando por base decisão do Supremo Tribunal Federal, determinaram-se padrões mínimos para que as decisões sejam capazes de atender as demandas específicas sem que haja comprometimento da atividade generalizada por parte do Estado. A escolha das decisões foi realizada por meio de pesquisa junto ao sítio oficial do Tribunal de Justiça do Estado do Maranhão considerando os termos "saúde - Estado - reserva do possível". As decisões analisadas referem-se aos últimos cinco anos. Já as decisões de tribunais superiores foram analisadas tomando-se como base os mesmos termos de procura bem como a repercussão da decisão STA 175, de 2009, cujo relator foi o Min. Gilmar Mendes.
\end{abstract}

Palavras-chave: Direito à saúde. Reserva do possível. Poder Judiciário. Estado.

Abstract: The study aims to at analyzing the judgments TJMA considering individual claims related to the execution and guaranteeing the right to health, from the offer of medical treatment / medication specific for the state. Analyze the reasons for decisions and actions of the judiciary before the defense justified as "possible reserves" by the public entity. Based on the theory of reserve for the state defends itself saying it is impossible to provide specific services or considering the general public health policy or financial matters. In turn, the judiciary is manifested sometimes claim considering the individual (most common position) now that possibility away. Based on the decision of the Supreme Court, it was determined minimum standards for decisions to be able to meet the specific demands without compromising the widespread activity by the state. The choice of the decisions was conducted through survey to the official Court of the State of Maranhão considering the terms "health - state - reserve the possible." The decisions analyzed refer to the last five years. Since the decisions of higher courts were analyzed taking as base the same search terms as well as the impact of the decision STA 175, 2009, which was the rapporteur Justice Gilmar Mendes.

Keywords: Right to health. Possible Reservation. The Judiciary Power. State.

Resumen: El trabajo tiene como objetivo analizar decisiones en juicios del TJMA considerando reclamaciones individuales relacionadas con la ejecución y garantía del derecho a la salud, a partir de la oferta de tratamiento médico / medicamento específico por el estado. Analizar las razones de las decisiones y acciones del poder judicial ante defensas justificadas como "reservas posibles" por la entidad pública. Sobre la base de la teoría de la reserva posible, el Estado se defiende diciendo que es imposible proporcionar servicios específicos, considerando la política general de salud pública o los asuntos financieros. Por su parte, el Poder Judicial se manifiesta a veces considerando la posición individual (posición más común) y otras veces desconsiderándola. Sobre la base de la decisión de la Corte Suprema de Justicia, se definieron las normas mínimas para que las decisiones sean capaces de satisfacer las demandas específicas sin comprometer la actividad generalizada por el estado. La elección de las decisiones se llevó a cabo mediante una encuesta oficial a la Corte del Estado de Maranhão, teniendo en cuenta los términos "salud - estado -. Reserva de lo posible" Las decisiones analizadas se refieren a los últimos cinco años. Por otro lado, las decisiones de los tribunales superiores fueron analizadas tomando como base los mismos términos de búsqueda, así como el impacto de la decisión STA 175 de 2009, relatada por el Ministro de la Justicia Gilmar Mendes.

Palabras clave: Derecho a la salud. Reserva posible. Poder Judicial. Estado.

Trabalho premiado durante o XXIV Encontro do SEMIC, realizado na UFMA entre os dias 05 a 08 de novembro de 2012.

*Artigo recebido em dezembro 2012

Aprovado em fevereiro 2013 


\section{INTRODUÇÃO}

O direito à saúde é fundamental e essencial à condição digna de ser humano. Tal fato é inquestionável e largamente reconhecido. Entretanto, o Estado brasileiro, seja em âmbito federal, estadual ou municipal tem se mostrado inadimplente com tal obrigação que lhe é constitucionalmente imputada.

Tornou-se comum ao cidadão procurar - Poder Judiciário para que este assegure tratamento médico ou medicamento essencial à sua sobrevivência. Da mesma forma, torna-se regra a defesa do Estado pautar-se na teoria da reserva do possível. Tem-se de um lado o cidadão que necessita de tratamento ou medicamento excepcional para a garantia mesmo de sua sobrevida, e de outro o Estado a argumentar que o atendimento desta demanda em particular pode gerar precedentes que dificultem o próprio caminhar da Administração Pública.

Desta forma, é objetivo deste artigo analisar até que ponto a teoria da reserva do possível é capaz de fundamentar a pretensão negativa do Estado, da mesma forma que se analisa como e quando, ou seja, com base em que regras o Poder Judiciário deve atender às muitas demandas nesta matéria.

Assim, tem-se num primeiro momento uma análise sobre a necessária garantia e efetivação do direito à saúde, sabendo-se que o mesmo é essencial para a continuidade da garantia da vida digna. Segue-se com a análise das questões relacionadas à saúde como um direito inquestionável do cidadão e dever constitucional do Estado, do qual este não pode se afastar.

Em continuidade, trata-se da delimitação da teoria da reserva do possível, comumente apresentada pelo Estado em sua defesa nas questões judiciais que envolvem prestação de serviços de saúde tido como excepcionais, para finalizar-se com a análise de decisões judiciais advindas do Tribunal de Justiça do Estado do Maranhão (TJMA) considerando casos concretos referentes a demandas por tratamentos médicos e medicamentos. Desta forma, tem-se que o objetivo principal desta análise é externar como o Judiciário maranhense vem tratando a questão da demanda pessoal pela efetivação do direito à saúde, bem como qual a consideração que se faz da teoria da reserva do possível.

\section{DA EFETIVIDADE DO DIREITO À SAÚDE A PARTIR DA ATUAÇÃO DO PODER JUDICIÁRIO}

Muitas são as demandas concernentes aos direitos à vida e à saúde. Diante disso, prioridades devem ser estabelecidas a fim de que não sejam relegados casos de extrema necessidade e urgência. Desta forma, vê-se maior espaço para decisões judiciais que realmente realizem a ponderação de valores e princípios.
Em face do princípio da reserva do possível, há situações em que o Poder Judiciário deve atentar a esta contingência de ordem econômica, bem como há aquelas em que a exigência não está apenas na mera alegação da inexistência de recursos.

Neste enlevo, apresentam-se quatro decisões do Tribunal de Justiça do Estado do Maranhão, nas quais a cláusula da reserva do possível ora é utilizada como argumento para a concessão ora para a não concessão de medicamentos e tratamentos especiais.

A primeira decisão, o Agravo Regimental no 008322-2009, aponta a concessão de medicamentos como um dever do Estado, em que a dignidade da pessoa humana deve sempre prevalecer em detrimento dos recursos orçamentários públicos. Neste contexto, a relatora Desa. Nelma Sarney Costa apresenta o acalorado confronto existente entre os princípios da reserva do possível e do mínimo existencial, no qual, segundo ela, deve haver uma prevalência deste sobre aquele. Além disso, o agravante alega a responsabilidade solidária entre os entes da Federação. Para a relatora, não cabe discutir a competência para o fornecimento de medicamento. Os direitos à saúde e à vida são direitos de todos e dever do Estado, direitos fundamentais entalhados na Constituição Federal.

Por sua vez, o Agravo de Instrumento no 022669-2010 impõe ao Estado o fornecimento de alimento especial, com responsabilidade solidária dos entes federativos. Concatenadas à dignidade da pessoa humana estão a vida e a saúde, sendo a garantia do direito à saúde uma obrigação do Estado; este não o fazendo espontaneamente, deve o Judiciário, em consonância com o princípio da inafastabilidade da jurisdição, impor o cumprimento de tal preceito constitucional. O relator Des. Cleones Carvalho Cunha aduz que o Poder Público não pode argumentar a reserva do economicamente possível sem que demonstre a real privação de recursos financeiros. Em seu voto, ele assevera:

O argumento da reserva do possível, levantada por
Estado do Maranhão, apesar de relacionar-se com as
limitações orçamentárias que o Estado, em sentido
amplo, possui, não tem o condão de obstar a garantia
do mínimo existencial, sob pena de negar a própria
efetividade de direitos fundamentais. O mínimo exis-
tencial constitui-se no conjunto de bens e utilidades
indispensáveis à vida humana digna, a exemplo do
direito à educação, à moradia e à saúde. Nesse pas-
so, devem ser tidos como prioridade no orçamento,
atendidos precipuamente, numa conciliação razoável
e proporcional com a reserva do possível. (MARA-
NHÃO, 2010)

Com estas decisões, percebe-se que por vezes os juízes desconsideram as alegações apresentadas pelos Gestores Públicos quanto à insuficiência dos recursos financeiros para a implementação de determinadas imposições judiciais. Apesar disso, encontram-se decisões 
no Poder Judiciário maranhense em que o princípio da reserva do possível é utilizado como argumento para a não concessão de medicamentos e tratamentos. Frise-se que as decisões a seguir apresentadas possuem o mesmo relator, o Des. Marcelo Carvalho Silva, e, inclusive, a mesma ementa. Tal fato demonstra uma mera repetição e, até mesmo, uma negligência do Judiciário em não rever seu posicionamento ou atualizar suas decisões baseando-se em novas fundamentações.

O Agravo de Instrumento no 17524- 2007 foi interposto pelo Estado do Maranhão, almejando reformular a decisão que impunha a obrigação de pagar a quantia mensal de $\mathrm{R} \$$ 1.500 (mil e quinhentos reais) ao agravado, como ajuda de custo de tratamento pós-operatório. Para o relator, prevalecendo a pretensão do agravado, haverá um caos na Administração Pública que desta forma estaria se obrigando a custear o tratamento de saúde de cada integrante da sociedade. Elucidando a reserva do possível e a disponibilidade dos recursos do Estado, ele aponta a necessidade da racionalização das despesas a fim de que se evitem gastos vultosos em benefício de um único indivíduo.

Sob o mesmo enfoque encontra-se o Agravo de Instrumento no 21212-2007. Alterando poucas palavras em seu voto, o relator Des. Marcelo Carvalho Silva afirma que, para a concretização dos direitos sociais, é preciso que se verifique a limitação e a carência de recursos. Para ele, a saúde, enquanto dever do Estado, deve ser implementada através de políticas públicas. Desse modo, o erário público não pode ser destinado a cada membro da sociedade individualmente considerado, já que isso motivaria a falência da máquina estatal.

Haja vista a polêmica e a complexidade que envolvem o tema é necessária uma análise mais aprofundada sobre a cláusula da reserva do possível, um princípio fundamental usado, muitas vezes, como argumento de defesa do Estado. Os recursos públicos são escassos, mas as demandas sociais são muitas, e exigese do Estado a prestação de mínimas condições de vida digna para a pessoa humana.

\section{DO DIREITO À SAÚDE}

Nada há de polêmico na afirmação de que a saúde é um direito constitucionalmente previsto. E não poderia ser diferente, tendo em vista a dupla fundamentalidade formal e material que carrega e compartilha com os demais direitos e garantias individuais .

O ponto central da questão recai no fato de que no Estado Social Democrático de Direito a concretização dos direitos fundamentais está diretamente subordinada ao orçamento público. E a relação entre este e as políticas públicas, atualmente, é inquestionável. Tendo esta premissa como certa, surge que a implementação do direito à saúde, não sendo ele uma elementar promessa inconsequente, deve ser concretizada . É em razão desta norma que os particulares tornam-se credores, pelo menos em tese, de prestações materiais relativas à saúde, como atendimento médico e hospitalar e/ou fornecimento de medicamentos (dimensão positiva do direito à saúde/ direito a prestações materiais) e ao direito de terem sua saúde resguardada contra qualquer ingerência estatal ou de terceiros (dimensão negativa do direito à saúde/ direito de defesa). Ambas as dimensões do direito à saúde geram custos para o Estado, como assim pontua José Casalta Nabais (2011, P. 12):

Do ponto de vista do seu suporte financeiro, bem podemos dizer que os clássicos direitos e liberdades, os ditos direitos negativos, são, afinal de contas, tão positivos como os outros, como os ditos direitos positivos. Pois, a menos que tais direitos e liberdades não passem de promessas piedosas, a sua realização e a sua proteção pelas autoridades públicas exigem recursos financeiros.

Tendo sido esclarecida as considerações iniciais, segue-se a caminho do tema central da polêmica questão envolvendo o direito à saúde, que, neste ponto, ganha substância na interrogação de se o direito à saúde seria ou não um direito subjetivo individual, ou seja, se ele poderia ser utilizado como fundamento em ações judiciais que requerem prestações materiais individuais, como um fármaco de alto custo ou o leito de um hospital. Partilha-se da opinião do professor Ingo Sarlet para o qual a resposta a esta indagação é tudo, menos singela.

Apesar da natureza problemática do assunto, é preciso esclarecer de antemão que, como a todos os direitos sociais, ao direito a saúde deverá ser concedida a máxima eficácia e efetividade. Isso quer dizer que, em sede de conflitos com outros princípios e valores constitucionais, o direito à saúde, em obediência a uma interpretação sistemática do direito, deve ser analisado com cautela e posto na ordem de preferência, pois não há que se conceber que a vida, bem maior tutelado pela Carta Magna, seja relegado a um plano não condizente com sua natureza de excelência e prioridade. Para constatar se estamos ou não diante de um caso que mereça tal superioridade, deve-se ater ao liame que divide uma vida digna de uma sobrevida de sofrimentos e, claro, ao bem-comum.

Como primeiro entrave a busca de respostas à indagação principal - se o direito à saúde seria ou não um direito subjetivo individual tem-se o fato de que o legislador, ao tratar do tema, não mencionou qual seria o objeto do direito à saúde, restringindo-se a uma simples noção genérica. O que fazer se não se sabe qual realmente é o dever do Estado no tocante à saúde? Estar-se-ia diante de um dever restrito a prestações básicas e vitais? Ou o legislador quis ir mais longe e decidiu enquadrar todo e qualquer tipo de prestação a que o cidadão esteja necessitado no momento em termos de saúde, como fornecimento de óculos, próteses, etc.? 
Sobre o assunto, Sarlet (2002, p.74) entende que:

Quem vai definir o que é o direito a saúde, quem vai, neste sentido, concretizar esse direito é o legislador Federal, Estadual e/ou Municipal, dependendo da competência legislativa prevista na própria Constituição. Da mesma forma, será o Poder Judiciário (ao menos, assim o sustentamos), quando acionado, quem irá interpretar as normas da Constituição e as normas infraconstitucionais que a concretizarem.

É fundamental acrescentar ao entendimento aqui exposto uma premissa básica da ciência econômica a qual informa que as demandas são ilimitadas, mas os recursos escassos. O legislador ao concretizar o direito à saúde por meio das políticas públicas, faz, ou ao menos se espera que faça, escolhas apoiadas em estudos e vinculadas aos limites constitucionais no âmbito da receita e despesa do orçamento público. Assim, segue-se que nem todas as necessidades da população em termos de saúde serão atendidas, pelo menos não custeadas pelo governo. Com isto, natural parece que as pessoas que se sintam lesadas provoquem o Judiciário para tentar conseguir o remédio, o leito de hospital ou tratamento, por exemplo, que necessitam. Discute-se, pois, se o Judiciário é a instituição apta a obrigar o Estado a concretizar a demanda buscada pelo cidadão.

O argumento mais utilizado atualmente para rebater as decisões que determinam o cumprimento de alguma obrigação desta natureza por parte do Estado é o de que seria economicamente impossível atender a todas as necessidades sociais, muito menos a de cada indivíduo. Importou-se assim a teoria da reserva do possível, "que passou a ocupar o lugar que antes era ocupado pela teoria das normas programáticas, pela separação dos poderes e pela discricionariedade administrativa (MÂNICA, 2007. p.169)".

E a reserva do possível a linha de defesa mais utilizada pela Administração Pública quando da tentativa de responder às demandas individuais ou mesmo coletivas relacionadas à prestação de serviços de saúde excepcionais. Desta forma, tem-se esta argumentação como a próxima questão enfrentada por este artigo.

\section{A TEORIA DA RESERVA DO POSSÍVEL}

Em 1960, a Alemanha adotou uma política de limitação do número de vagas em cursos superiores. Por esta razão, e por não conseguirem vagas no curso desejado, um grupo de estudantes entrou com uma ação judicial requerendo vagas no curso de Medicina. Como fundamento da ação, foi utilizado o art.12 da Lei Fundamental da Alemanha, que dispõe da seguinte forma: "Todos os alemães têm direito a escolher livremente sua profissão, local de trabalho e seu centro de formação".

$\mathrm{Na}$ decisão, o Tribunal Constitucional Alemão concluiu que o direito a prestação positiva requerida pelos demandantes estava sujeito a cláusula da reserva do possível, ou seja, a sua demanda teria que condizer com o que todo cidadão pode razoavelmente esperar da sociedade. Nas palavras de Ingo Sarlet (2002, p. 17):

\begin{abstract}
A prestação reclamada deve corresponder ao que o indivíduo pode razoavelmente exigir da sociedade, de tal sorte que, mesmo em dispondo o estado de recursos e tendo poder de disposição, não se pode falar em uma obrigação de prestar algo que não se mantenha nos limites do razoável.
\end{abstract}

A teoria foi importada para o Brasil com uma roupagem tão peculiar que está mais para uma nova linha argumentativa, cuja denominação foi escolhida como teoria da reserva do financeiramente possível. Para esta, o entrave à concreção dos direitos fundamentais estaria em sede da insuficiência de recursos públicos e da falta de previsão orçamentária da respectiva despesa. Em termos práticos, a teoria propugna que ao decidir a questão o juiz não pode determinar o cumprimento de uma obrigação que o réu não possa realizar sem um grave prejuízo nas contas públicas, colocando em risco o cumprimento dos outros deveres já determinados na previsão orçamentária.

Os críticos da famosa teoria afirmam que a vida é o bem jurídico maior. Para estes, o Estado não pode assistir impassível à morte de um cidadão por falta de recursos que assegurem seu tratamento quando milhões em verbas públicas são desviadas rotineiramente pelos gestores ímprobos, por exemplo. As somas desviadas deveriam ser utilizadas na construção de postos de saúde e hospitais, na realização de campanhas de saúde preventiva e ainda em ações diretamente relacionadas com a questão da saúde, como educação. Neste sentido Américo Bedê Freire Júnior (2005, p.14) destaca:

Será que é possível falar em falta de recursos para a saúde quando existem, no mesmo orçamento, recursos com propaganda do governo? Antes de os finitos recursos do Estado se esgotarem para os direitos fundamentais, precisam estar esgotados em áreas não prioritárias do ponto de vista constitucional e não do detentor do poder.

Apesar das críticas à teoria da reserva do possível no Brasil, também aqui se defende sua utilização como argumento racional nas decisões acerca desta temática, no entanto, com a condição de estar atrelada a alguns parâmetros.

Portanto, não se trata de enquadrar a decisão num drama em que se escolhe entre a vida ou a morte. Acontece que não se podem ignorar os impactos econômicos das ações individuais, principalmente quando estão em iminência de atingir um número indeterminado de inocentes. O orçamento público é comprometido e vinculado e, desta forma, quando uma decisão obriga que seja pago o que não estava previsto no orçamento, com certeza outra área será prejudicada.

Defendendo opinião análoga, a ex Ministra Ellen Gracie (apud FORTUNA, 2009, p, 9) se pronunciou nesses termos: 
Com efeito, a gestão da política nacional de saúde, que é feita de forma regionalizada, busca uma maior racionalização entre o custo e o benefício dos tratamentos que devem ser fornecidos gratuitamente, a fim de atingir o maior número possível de beneficiários. Entendo que a norma do art. 196 da Constituição da República, que assegura o direito à saúde, refere-se, em princípio, à efetivação de políticas públicas que alcancem a população como um todo, assegurandoIhe acesso universal e igualitário, e não a situações individualizadas. [...]

No presente caso, ao se deferir o custeio do medicamento em questão em prol do impetrante, está-se diminuindo a possibilidade de serem oferecidos serviços de saúde básicos ao restante da coletividade.

Surge que quando da análise desses casos, deve-se ter em mente alguns critérios para concessão, apesar de estar-se ciente que há peculiaridades em cada caso, é preciso seguir parâmetros para manter a fundamental segurança jurídica do Estado de Direito.

Antes de qualquer outro critério, o princípio do mínimo existencial destaca-se numa pretensa hierarquia de princípios. Ele se caracteriza, em termos práticos, na análise de se a prestação material ora requerida pelo autor da ação é absolutamente indispensável para manutenção do mínimo à continuação de sua vida. Neste sentido, segue o raciocínio de GuiIherme Kfouri (apud FORTUNA, 2009, p, 9):

A valorização da vida ocupa, sem dúvida, o posto mais importante na hierarquização dos argumentos, prevalecendo em todos os casos em que o tratamento se mostra indispensável para a manutenção da vida e a sua dispensa incorre em sério risco de produzir o denominado "dano inverso", ou seja, conseqüências irreparáveis, como a morte, por exemplo.

Outro parâmetro que mantém relação com todas as decisões que determinam prestações materiais individuais com relação à saúde, e tão importantes quanto o supracitado critério é a chamada comprovação da exaustão orçamentária pelo réu. É o que se entende da doutrina especializada e dos julgados, como se infere da análise da paradigmática decisão citada abaixo:

Cumpre advertir, desse modo, que a cláusula da "reserva do possível" - ressalvada a ocorrência de justo motivo objetivamente aferível - não pode ser invocada, pelo Estado, com a finalidade de exonerar-se do cumprimento de suas obrigações constitucionais, notadamente quando, dessa conduta governamental negativa, puder resultar nulificação ou, até mesmo, aniquilação de direitos constitucionais impregnados de um sentido de essencial fundamentalidade. (STF, ADPF n.45, Rel. Min. Celso de Mello, julg.29.04.04, grifo nosso).

No caso específico dos medicamentos, destacam-se os critérios colhidos durante a audiência pública sobre saúde, organizada pelo ministro Gilmar Mendes, nos dias 27, 28 e 29 de abril, e 4, 6 e 7 de maio de 2009, e que contou com a presença de todos que de alguma forma possuem relação com a distribuição de medicamentos, tais sejam doentes crônicos, médicos, farmacêuticos, representantes da União, Estados, Municípios e dos Conselhos de Medicina, dentre outros.
Os parâmetros estabelecidos para a concessão de medicamentos foram expostos na decisão STA 175, cujo relator foi o Ministro Gilmar Mendes. A seguir os critérios que devem ser seguidos:

\begin{abstract}
i) verificar se há política estatal que abranja a prestação à saúde pleiteada; caso haja, a determinação judicial de seu cumprimento não caracteriza criação de política pública pelo Poder Judiciário, razão por que o direito subjetivo é evidente;
\end{abstract}

ii) se não houver política pública, em havendo vedação legal, como por exemplo ausência de registro na ANVISA, a princípio não poderia ser deferido o tratamento pelo Poder Judiciário; o registro seria condição necessária para atestar a segurança e o beneficio do produto, o quem todavia, não é visto de forma absoluta;

iii) verificar se há motivação para o não fornecimento da medicação pelo Poder Público, como por exemplo, se não há evidências científicas para autorizar a inclusão do tratamento; neste caso, segundo o Ministro Gilmar Mendes, pode ocorrer do SUS fornecer tratamento alternativo, mas não adequado a determinado paciente, o que ensejará necessidade de prova neste sentido; se não houver tratamento do SUS, é preciso diferenciar os experimentais dos novos tratamentos ainda não testados pelo SUS. Os experimentais ficam afastados da concessão pelo Poder Judiciário, sendo que, quanto aos tratamentos novos, deve-se ter parcimônia nas decisões. Destacou o Ministro que apesar dos protocolos privilegiarem a melhor distribuição de recursos públicos e a segurança dos pacientes, a aprovação de novas indicações pode ser lenta e comprometer o acesso ao tratamento já utilizado na rede privada;

iv) Imprescindibilidade de instrução processual

(STA 175, Relator(a): Min. Presidente Gilmar Mendes, julgado em 18/09/2009) (BRASIL, 2009)

Vê-se que há uma linha razoável de previsibilidade e argumentação a ser utilizada pelo Poder Judiciário em qualquer esfera, em qualquer instância. Não há, portanto, motivo para decisões isoladas, sem que padrões mínimos de fundamentação geral sejam atendidos. Diante disto, analisa-se a seguir a atuação do Poder Judiciário maranhense, tomando-se como exemplo demandas levadas ao Tribunal de Justiça do Estado do Maranhão, tendo em comum tais decisões a questão relevante da efetivação do direito à saúde por meio de diferenciado tratamento médico custeado pelo Estado.

\section{A ATUAÇÃO DO TJ/MA NA EFETIVAÇÃO DO DIREITO À SAÚDE CONSIDERANDO A RESERVA DO POSSÍVEL}

Na primeira decisão analisada, tal seja o Agravo Regimental n008322-2009, o princípio da reserva do possível, utilizado como argumento pelo agravado para não conceder a medicação, foi rebatido sem maiores discussões. Como apontou a Desa. Nelma Sarney Costa, o fármaco buscado está contido na lista de medicamentos do Programa de Medicamentos Excepcionais que devem ser concedidos aos que necessitarem dele. $\mathrm{O}$ argumento está em consonância com o que dispõe um dos critérios elencados pelo ministro Gilmar Mendes: 
i) verificar se há política estatal que abranja a prestação à saúde pleiteada; caso haja, a determinação judicial de seu cumprimento não caracteriza criação de política pública pelo Poder Judiciário, razão por que o direito subjetivo é evidente.

Apesar do argumento acima ser suficiente para fundamentar sua decisão, a relatora ainda observa que o medicamento é essencial para manter o "mínimo existencial" da cidadã demandante.

Chama-se a atenção para determinado trecho do voto, in verbis:

Ademais, mesmo que se entendesse pela prevalência do Princípio da Reserva do Possível em detrimento da Dignidade da Pessoa Humana, não merece guarida o argumento do ora Agravante de que o fornecimento do medicamento ENBREL à Impetrante pudesse causar um déficit no orçamento do Estado.

Se fosse o caso de se assumir o argumento do princípio da reserva, seria necessária, como já mencionada, a comprovação de exaurimento orçamentário. Será este documento que irá demonstrar se haverá ou não um déficit no orçamento do Estado, e não uma suposição. Como a relatora em nenhum momento menciona que foi requerido ao Estado este documento, entende-se que, neste ponto, realizou-se uma precipitação em sua conclusão.

A iniciativa de aplicar uma multa diária pelos dias de atraso no cumprimento da decisão é legal e condizente com as formas coercitivas utilizadas em outros julgados do país:

A hipótese dos autos cuida da possibilidade de bloqueio de verbas públicas do Estado do Rio Grande do Sul, pelo não - cumprimento da obrigação de fornecer medicamentos a pessoa portadora de doenças graves, como meio coercitivo para impor o cumprimento de medida antecipatória ou de sentença definitiva da obrigação de fazer ou de entregar coisa (arts.461 e 461-A do CPC). (STJ, Resp n॰ 874.630/RS, Segunda Turma, Rel. Min. Humberto Martins). (BRASIL, 2006)

No Agravo de Instrumento n.o 370/2011, a relatora, Desa. Nelma Sarney Costa inicia seu voto afirmando que a dignidade humana, o direito a vida e a saúde devem ter prioridade no caso em análise. A seguir recorre, implicitamente, ao princípio do mínimo existencial, ao afirmar que deve ser concedida a demanda, pois o autor da ação corre risco de ver sua doença agravada caso não seja satisfeito seu pedido.

Ressalta-se um argumento relevante levantado pela relatora e que não foi encontrado na decisão acima analisada, qual seja o da comprovação da impossibilidade financeira do autor da ação em custear ele próprio o que ora requer do Estado. A importância desta comprovação reside no fato, já mencionado, de que as decisões desta natureza devem fundamentar-se nos mais diversos critérios, para que não incorra no erro de obrigar o cumprimento de prestações ao comprometido orçamento público que sejam injustas para com o bem comum.

Com relação ao princípio da reserva do possível, a relatora afirma que ele só pode ser aludido quando o mínimo existencial, que deve ser garantido a todo cidadão, estiver sido cumprido, caso não, há a impossibilidade do uso deste princípio como argumento procedente.

$\mathrm{Na}$ decisão do Agravo de Instrumento $\mathrm{n}^{\mathrm{o}}$ 17524- 2007, o relator Des. Marcelo Carvalho Silva conduz o princípio da reserva do possível como argumento principal para a não concessão da prestação individual ora requerida. O relator critica o fato de não ter sido requerida a prova de exaurimento do orçamento público. Seu relato continua defendendo que os direitos sociais devem ser concretizados via políticas públicas, que o objeto do direito à saúde são prestações genéricas e de maneira alguma contêm promessas individuais. Além disto, ele alerta para o perigo que há em conceder este tipo de demanda, tendo em vista o consequente efeito multiplicador daquelas decisões, que pode levar o Estado à falência .

Na decisão, o Des. Marcelo Carvalho em nenhum momento concedeu relevância às condições de saúde do autor da ação, não realizando um confronto entre o princípio do mínimo existencial e o princípio da reserva do possível, se afastando desta forma do entendimento da maioria dos julgados brasileiro nesta seara, tendo em vista que este é o primeiro critério utilizado como triagem nas decisões.

Seguindo com sua forma peculiar de decidir, o relator mais uma vez deixa de lado a análise das reais condições orçamentárias, pois, apesar de criticar o fato de não ter sido requerido o documento que comprova o exaurimento orçamentário, ele chega a sua decisão sem a fundamental análise do documento.

$\mathrm{Na}$ decisão do Agravo de Instrumento $\mathrm{n}^{\circ}$ 21212/2007, cujo relator é o mesmo da decisão acima analisada, Des. Marcelo Carvalho, não há maiores considerações a fazer, tendo em vista que foi utilizada a mesma argumentação, com modificação de poucas palavras. Tornase aqui dever nosso lembrar as palavras do Min. Gilmar Mendes, que numa decisão paradigmática alertou:

Além disso, não procede a alegação de temor de que esta decisão sirva de precedente negativo ao Poder Público, com possibilidade de ensejar o denominado efeito multiplicador, pois a análise de decisões dessa natureza deve ser feita caso a caso, considerando-se todos os elementos normativos e fáticos da questão jurídica debatida (grifou-se) (Agr. 175/CE. Relator Min. Gilmar Mendes. Julgado 17/03/2010). (BRASIL, 2010).

Curioso notar que as palavras do Ministro proferidas em seu voto numa decisão citada pelo Des. Marcelo Carvalho justamente na decisão já comentada, depois reproduzida em outro voto.

Vê-se que o TJMA tem se mostrado sensível às demandas relacionadas à efetivação e garantia do direito à saúde através de questões particulares e individuais. O atendimento de tais pretensões abre caminho para casos idênticos seguirem pela mesma trilha: diante da inação do Estado em cumprir com papel 
que Ihe é essencialmente atribuído, busca o cidadão comum a guarida do Poder Judiciário, a fim de ver efetivada garantia que de pronto deveria Ihe ser estendida.

\section{CONSIDERAÇÕES FINAIS}

Não é de hoje que se questiona a capacidade do Estado brasileiro em prestar, de maneira digna, serviços públicos como os de saúde. Seja em razão das dificuldades operacionais, em um país de grande extensão, seja em razão do notório descaso do Executivo com as políticas de saúde pública, o fato é que o cidadão tem ficado cada vez mais à mercê da discricionariedade administrativa, quando determinados tratamentos ou procedimentos médicos são ofertados enquanto outros, mais complexos, dependem de determinação expressa do poder Judiciário, evidentemente após a provocação do interessado.

Ao se deparar com necessidades especiais urgentes, o que é sempre comum quando se trata de questões relacionadas à saúde, o indivíduo acaba por ver efetivado o mandamento constitucional do direito à saúde em momento posterior, ou seja, quando outro poder estatal, neste caso o Judiciário, determina que o Estado cumpra com suas obrigações essenciais.

Ainda que se discuta sobre a possibilidade de onerar pesada e individualmente o Estado, considerando que o normalmente solicitado são tratamentos caros e para uma pessoa em especial, não há como se justificar a ausência do Estado de questão tão relevante. Além do mais, sabe-se até mesmo por senso comum que o Estado brasileiro gasta muito e gasta mal. Como indicado neste artigo, muitos recursos do orçamento público são desviados pela prática comum da corrupção e servem a interesses particulares, em detrimento das questões coletivas, como a saúde. Interessante é perceber que é justamente a ausência de recursos, ou seja, a insuficiência orçamentária que serve de maneira mais comum à defesa do Estado, quando demandado em juízo, para não atender questões individuais.

A teoria da reserva do possível tem se tornado o meio automático de justificar a inação do Estado junto às políticas de efetivação do direito à saúde. E ao analisar esta defesa, o Judiciário maranhense tem se mostrado favorável à pretensão dos demandantes privados, ou seja, reconhece a fragilidade da teoria da reserva do possível e consequentemente afirma o dever do Estado em prestar serviços de saúde, ainda que especializados, aos que não podem arcar com seus custos junto ao sistema particular de atendimento médico.

Desta forma, o que se depreende das decisões analisadas é que o Estado é falho em não se organizar do ponto de vista orçamentário, e não pode, em consequência, deixar o cidadão em situação de risco. Não é só o Judiciário do Maranhão que tem decidido por afastar a viabilidade da reserva do possível, ainda mais considerando a decisão relatada pelo Min. Gilmar Mendes, determinando padrões mínimos e razoáveis de atendimento para estas questões. Assim, vê-se que apesar de não haver força obrigatória de precedente judicial de maneira generalizada, no Judiciário brasileiro, se espera, a partir da previsibilidade e coerência das decisões, que o direito à saúde seja realmente garantido e efetivado como determina a Constituição Federal.

\section{NOTAS}

1. Acadêmica do curso de Direito da Universidade Federal do Maranhão (UFMA). Bolsista de Iniciação Científica. Pesquisadora do Núcleo de Estudos em Direito e Desenvolvimento (NEDD/UFMA).

2. Acadêmica do curso de Direito da UFMA. Bolsista de Iniciação Científica (CNPq). Pesquisadora do NEDD/UFMA.

3. Doutora em Direito (UFSC). Professora dos cursos de graduação e pós-graduação (Mestrado) em Direito na UFMA. Professora do curso de Pós-Graduação em Cultura e Sociedade (Mestrado) da UFMA. Coordenadora do NEDD/UFMA. Avaliadora do MEC/INEP. Orientadora

4. Para Ingo Sarlet (2002, p. 3), "A fundamentalidade formal encontra-se ligada ao direito constitucional positivo[...] Já no que diz com a fundamentalidade em sentido material, esta encontra-se a relevância do bem jurídico tutelado pela ordem constitucional."

5. "O caráter programático da regra inscrita no art.196 da Carta Política[...] não pode converter-se em promessa constitucional inconseqüente, sob pena de o poder público, fraudando justas expectativas nele depositadas pela coletividade, substituir, de maneira ilegítima, o cumprimento de seu impostergável dever, por um gesto irresponsável de infidelidade governamental ao que determina a própria Lei Fundamental do Estado." Ministro Celso Bandeira de Mello. (Extraído das transcrições efetuadas no Boletim Informativo do STF, por ocasião do julgamento do Recurso Extraordinário $n^{\circ}$ 267.612-RS).

6. Os limites a receita são aqueles que dizem respeito aos princípios constitucionais tributários, como o princípio da legalidade tributária, da anterioridade e da capacidade contributiva. Os limites a despesa podem ser subdivididos em limites formais e materiais. Os formais são encontrados em dispositivos como o art.212 da CF-88 e os materiais estão consubstanciados nos valores, objetivos e programas estabelecidos na Constituição.

7. Acerca do tema efeito multiplicador das decisões (SEGATO, 2009). Supremo vai decidir se o Estado deve assegurar remédios caros para todos. 


\section{REFERÊNCIAS}

BRASIL. STF 175. Relator: Min. Presidente Gilmar Mendes, julgado em 18/09/2009. DJe182, Brasília, DF, 28 set. 2009. RDDP n. 81, 2009. p. 161-166. Disponível em: <www.stf. jus.br>. Acesso em: 10 ago. 2011.

. Agr. 175/CE. Relator Min. Gilmar Mendes, julgado em 17/03/2010. 2010. Disponível em: <www.stf.jus.br>. Acesso em: 10 ago. 2011.

STJ. Resp n 874.630/RS, Segunda Turma, Rel. Min. Humberto Martins, julg. 21.09.06. Brasília, DF, 21 set. 2006.

FORTUNA, Affonso de Aragão Peixoto. As responsabilidades quanto à prestação de ações e serviços públicos de saúde. Disponível em: <http://www.stf.jus.br/ arquivo/cms/processoAudienciaPublicaSaude/ anexo/As_responsabilidades_quanto_a_ prestacao_de_acoes_e_servicos_de_saude Procuradoriageral_do_Municipio_de_Joinville. pdf >. Acesso em: 10 ago. 2011.

FREIRE JÚNIOR, Américo Bedê. O controle judicial de políticas públicas. São Paulo: Revista dos Tribunais, 2005.

GRAU, Eros Roberto. Despesa pública conflitos entre princípios e eficácia das regras jurídicas - o princípio da sujeição da Administração as decisões do poder Judiciário e o princípio da legalidade da despesa pública: parecer. Revista Trimestral de Direito Público, n. 2, 1993.

KFOURI, Guilherme Bruno. Concessão de medicamentos pelo Supremo Tribunal Federal: análise argumentativa sobre as decisões da presidência da Ministra Ellen Gracie. 2009. Disponível em: <http:// www.egov.ufsc.br/portal/sites/default/files/ anexos/15184-15185-1-PB.pdf>. Acesso em: 10 ago. 2011.
KRELL, Andreas. Direitos sociais e controle judicial no Brasil e na Alemanha: os (des) caminhos de um direito constitucional comparado. Porto Alegre: Fabris, 2002.

MÂNICA, Fernando Borges. Teoria da reserva do possível: direitos fundamentais a prestações e a intervenção do Poder Judiciário na implementação de políticas públicas. Revista Brasileira de Direito Público, Belo Horizonte, ano 5, n.18, p.169-186, jul./ set.2007.

MARANHÃO. Tribunal de Justiça. Agravo de instrumento processo no 022669-2010/ MA. Rel. Des. Cleones Carvalho Cunha, julgamento em: 02/09/10. Diário da Justiça Eletrônico, São Luís, n. 172, p. 59, 22 set. 2010. Disponível em: <http://www3.tjma. jus.br:8080/diario/VisulizacaoDiarioPDF. mtw? idDiario $=610>$. Acesso em: 20 ago. 2011.

NABAIS, José Casalta. A face oculta dos direitos fundamentais: os deveres e os custos dos direitos. Disponível em: <http://www. agu.gov.br/Publicacoes/Artigos/05042002Jos eCasaltaAfaceocultadireitos_01.pdf >. Acesso em: 10 ago. 2011. p. 12

SARLET, Ingo Wolfgang. Algumas considerações em torno do conteúdo, eficácia e efetividade do direito a saúde na constituição de 1988. Revista Diálogo Jurídico, Salvador, CAJ - Centro de Atualização Jurídica, $\mathrm{n}^{\circ} .10$, janeiro, 2002. Disponível em: < http://egov.ufsc.br/portal/ sites/default/files/anexos/31953-37383-1-PB. pdf $>$. Acesso em: ago. 2011.

SEGATO, Cristiane. Supremo vai decidir se o Estado deve assegurar remédios caros para todos. Época. 2009. Disponível em: <http://revistaepoca.globo.com/Revista/ Epoca/0,,EMI73091-15223-2,00-supremo+v ai+decidir+se+o+estado+deve+assegurar+ remedios+caros+para+todos.html>. Acesso em: 10 ago. 2011. 